\title{
Dyeing and thermal behavior of jute fibre grafted with nitrile monomer
}

\author{
Md Ibrahim H Mondal ${ }^{*}$ and Md Khademul Islam
}

\author{
*Correspondence: \\ mihmondal@yahoo.com \\ Polymer and Textile \\ Research Lab., Department \\ of Applied Chemistry \\ and Chemical Engineering, \\ Rajshahi University, Rajshahi, \\ Bangladesh
}

\begin{abstract}
Modification of bleached jute fibre was carried out by graft co-polymerization with the vinyl monomers, acrylonitrile and methacrylonitrile. $\mathrm{A} \mathrm{K}_{2} \mathrm{~S}_{2} \mathrm{O}_{8} / \mathrm{FeSO}_{4}$ redox system was used in the presence of air. The graft yield and grafting efficiency increased with the increase of monomer, initiator and reaction time up to certain values, thereafter it decreased. This is due to the increasing rate of homopolymerization, rather than grafting, at the higher monomer concentration. The maximum graft yield with acrylonitrile and methacrylonitrile, under optimized conditions, was 19.78 and $43.15 \%$, respectively. The graft yield of methacrylonitrile is greater than that of acrylonitrile. This is due to the $-\mathrm{CH}_{3}$ group present in methacrylonitrile. The inclusion of nitrile monomer onto the treated fibre was identified by Fourier Transform Infrared Spectroscopy. The surface morphology and thermal behavior of the modified fibre was investigated by Scanning Electron Microscopy and Thermogravimetric Analysis. Modification of jute fibre improved the thermal stability, breaking strength as well as dyeability of the fiber.
\end{abstract}

Keywords: Jute, Grafting, Nitrile monomer, Thermal stability

\section{Introduction}

Jute fibre is the most important cash crop and the biggest foreign exchange earner of Bangladesh. It is composed of $60-70 \% \alpha$-cellulose, $15-20 \%$ hemicelluloses, $5-10 \%$ lignin and $3-5 \%$ pectins, together with some fatty acid and waxy matter (Alam and Khan 2007). In recent years, it has been threatened by increasing competition from cheap synthetic fibres. Due to environmental issues, many ecofriendly alternative fibres and chemical modifications have been considered by researchers (Mishra et al. 2001; Gonaslves and Mungara 1996). So it is necessary to improve the quality of jute fibre for commercial utilization, to meet total fabric requirements of the importing countries as well as to minimize the import of competing synthetic fibres.

Various chemical treatments have been used to improve the physico-chemical performance of natural fibres in the past (Ouajai et al. 2007; Mohanty et al. 2000; Dong et al. 2015). Although a lot of work has been reported on graft co-polymerization of vinyl monomers onto cellulosic and other textile fibre (Mondal 2013; Bakr et al. 2015), much less has been reported on grafting of nitrile monomers onto jute fibre. Yet jute is an important lignocellulose fibre.

Depending on the chemical structure of the monomer grafted onto cellulose, graft copolymer gain new properties such as improved elasticity, hydrophobic character

(C) 2015 Mondal and Islam. This article is distributed under the terms of the Creative Commons Attribution 4.0 International License (http://creativecommons.org/licenses/by/4.0/), which permits unrestricted use, distribution, and reproduction in any medium, provided you give appropriate credit to the original author(s) and the source, provide a link to the Creative Commons license, and indicate if changes were made. 
(Bicak et al. 1999; Okieimen 1987), heat resistance (Samal et al. 1988; Misra et al. 1987; Huque et al. 1980), resistance to microbial attack (Mcdowall et al. 1984), abrasion resistance (Bianchi et al. 2000). Grafting also changes the mechanical properties of grafted polymer varied with the amount of grafting (Ouajai et al. 2004; Fatimah et al. 2014; ElShekeil et al. 2014) and the grafting led little degradation effect on mechanical properties. Hence, it is expected that the properties of this fibre on modification by grafting, can be improved for use in the manufacture of high-quality products.

Therefore chemical modification, through graft co-polymerization, of nitrile monomer on to jute fibres, has been receiving considerable interest in recent years. The grafting was determined on the basis of the increased weight of the fibre treated. In the present work, attempts have been made to modify the jute fibre with acrylonitrile (AN) and methacrylonitrile (MAN) monomers, initiated under a potassium persulphate $\left(\mathrm{K}_{2} \mathrm{~S}_{2} \mathrm{O}_{8}\right)$ and ferrous sulphate $\left(\mathrm{FeSO}_{4}\right)$ redox system. The study attempted to determine the optimum grafting conditions for such modification. Some physico-chemical characteristics of the grafted fibre were investigated.

\section{Methods}

\section{Materials}

Raw jute fibre (Corchorus olitorius, Tossa Variety) was collected from Rajshahi Jute Mill Ltd., Bangladesh. Glacial acetic acid, anhydrous sodium acetate, sodium chlorite, acrylonitrile, methacrylonitrile, potassium persulphate, ferrous sulphate and the dyestuffs were purchased from BDH, England.

\section{Sample preparation}

The collected jute fibre were carefully combed, blended and washed with $6.5 \mathrm{~g}$ of detergent and $3.5 \mathrm{~g}$ of soda per litre at $75^{\circ} \mathrm{C}$ for $30 \mathrm{~min}$ (Farouqui and Mondal 1989). The jute fibre was bleached, with a sodium chlorite solution of concentration $0.5 \%$, at $\mathrm{pH} 4$ and at $80-90^{\circ} \mathrm{C}$, for $90 \mathrm{~min}$ (Farouqui and Mondal 1989). Then the bleached jute fibre was grafted with acrylonitrile and methacrylonitrile monomers.

\section{Method of grafting}

The graft copolymerization of jute fibre was carried out in a $100 \mathrm{~mL}$ stoppered Erlenmeyer flask. Polymerization was done with $240-330 \%$ monomer, $18-25 \% \mathrm{~K}_{2} \mathrm{~S}_{2} \mathrm{O}_{8}$ as initiator and 1-6\% $\mathrm{FeSO}_{4}$ as catalyst, based on the weight of the fibre. Polymerization took $30-150 \mathrm{~min}$, at $60-110^{\circ} \mathrm{C}$ in the fibre-liquor ratio of 1:50. At the end of the desired period, the jute fibre was washed repeatedly three times with warm distilled water and dried (Hebiesh et al. 1971; EL-Rafie et al. 1974). Graft yield and grafting efficiency were calculated according to the following formula:

$$
\begin{aligned}
\text { Graft yield, } \% & =\frac{W_{1}-W_{0}}{W_{0}} \times 100 \\
\text { Grafting efficiency, } \% & =\frac{W_{1}-W_{0}}{W_{2}} \times 100
\end{aligned}
$$

where $W_{1}$ is the weight of the grafted jute fibre after modification, $W_{0}$ is the weight of ungrafted jute fibre before modification and $\mathrm{W}_{2}$ is the weight of monomer used. 
IR spectroscopy

Fourier Transform Infrared Spectroscopy (FTIR) spectroscopy analysis was performed, using a Perkin Elmer 100 infrared spectrometer. The fibres and $\mathrm{KBr}$ (potassium bromide) were dried in an oven at $105^{\circ} \mathrm{C}$, until they were moisture-free. Then about one percent fibre was mixed with dried $\mathrm{KBr}$, ground into powder, using a mortar pestle (Mondal 2013). The infrared spectra of the samples were recorded with FTIR between 400 and $4,000 \mathrm{~cm}^{-1}$.

\section{Thermal analysis}

Thermogravimetric analysis was used to characterize the thermal decomposition rate and the thermal stability of the raw and grafted fibre. The samples, approximately $10 \mathrm{mg}$ each, were heated from 30 to $600^{\circ} \mathrm{C}$. Heating was done in an inert atmosphere (argon), at a rate of $20^{\circ} \mathrm{C} / \mathrm{min}$, in a Seiko-extar-TG/DTA-6300, Tokyo, Japan.

\section{Scanning electron microscopy}

Scanning electron microscopy (SEM) was performed. An SEM (FEI Quanta Inspect, Model: S50, Kyoto, Japan was used to observe the surface microstructure of the treated and untreated fibres.

\section{Method of dyeing}

Dyeing of bleached and modified jute fibres was carried out with direct and reactive dyes. The dye concentration of reactive and direct dyes were 3 and 1\%, and the electrolyte concentration for the dyes were 7 and $25 \%$ respectively.

\section{Tensile strength measurement}

The tensile strength of the jute fibres was measured, using a tensile strength tester (Serigraph machine 4004, Japan). Jute fibres were cut into equal pieces, $30 \mathrm{~cm}$ in length, and the length of each specimen between the jaws was maintained at $10 \mathrm{~cm}$. One twist per $2 \mathrm{~cm}$ was given, along the length of the fibre between the jaws of the machine. The average breaking load (the mean of 10 readings) of the fibre was measured in $\mathrm{kg} / \mathrm{Yarn}$. Tenacity was calculated by the formula 9 (ISO 5081-1977(E) 1997).

$$
\text { Tenacity }=\frac{\text { Average breaking load }}{\text { Denier }} \times \frac{\mathrm{g}}{\text { Denier }}
$$

where,

$$
\text { Denier }=\frac{\text { Weight of the sample in grams }}{\text { Length of the sample in meters }} \times 9,000 \text {. }
$$

\section{Method of sunlight exposure}

The jute sample was exposed directly, on a flat board, to sunlight, without any protection from weathering but was protected from rain, snow etc. At the same time and in the same place, bleached and grafted jute fibres were exposed to sun on the roof of a building in the months of April to July for $7 \mathrm{~h}$ each day. This continued for a total of $350 \mathrm{~h}$. 


\section{Method of heating}

Jute sample was placed in an electric oven, in the presence of air, at $30-160^{\circ} \mathrm{C}$ for $3 \mathrm{~h}$. Its breaking strength was then measured as described above.

\section{Results and discussion}

\section{Optimization of graft copolymerization}

The effect of the monomer concentration (AN and MAN) on polymerization of bleached jute fibre in the presence of a $\mathrm{K}_{2} \mathrm{~S}_{2} \mathrm{O}_{8} / \mathrm{FeSO}_{4}$ redox system, is shown in Fig. 1 . The graft yield increased with the increase of monomer concentration for both AN and MAN. After a certain value, it decreased with a further increase in the monomer concentration (Samal et al. 1986, 1989). The latter is due to the increasing homopolymerization rate rather than to grafting at the higher monomer concentration. The maximum graft yield was obtained when the bleached jute fibre was treated with 300\% AN and 280\% MAN. Their grafting efficiencies are 4.50 and $11.00 \%$, respectively.

Figure 2 shows that the graft yield and grafting efficiency increased with the increase of $\mathrm{K}_{2} \mathrm{~S}_{2} \mathrm{O}_{8}$ concentration as initiator, up to $22 \%$ for AN and $20 \%$ for MAN. The increasing trend of the graft yield might be the result of the formation of a large number of grafting sites on the cellulose backbone of the jute fibre. At the high initiator concentration, a large number of activated monomers become available. These turn to the formation of homopolymers, causing a shortage of monomer in the vicinity of the cellulose macroradicals. Hence, the graft yield and grafting efficiency start to decrease. The retarding effects of graft yield and grafting efficiency at higher concentration of $\mathrm{K}_{2} \mathrm{~S}_{2} \mathrm{O}_{8}$ may be due to the predominance of homopolymerization over grafting. The termination of growing grafted chain is caused primarily by free radicals, resulting from the decomposition of excess initiator and production of excess Fe(III) (Mukhopadhyay et al. 1975; Misra et al. 1987; Mohanty et al. 1986).

Figure 3 shows that the percent graft yield increased with the increase of $\mathrm{FeSO}_{4}$ concentration, up to $2 \%$, for both $\mathrm{AN}$ and MAN. Thereafter, percent graft yield decreased.

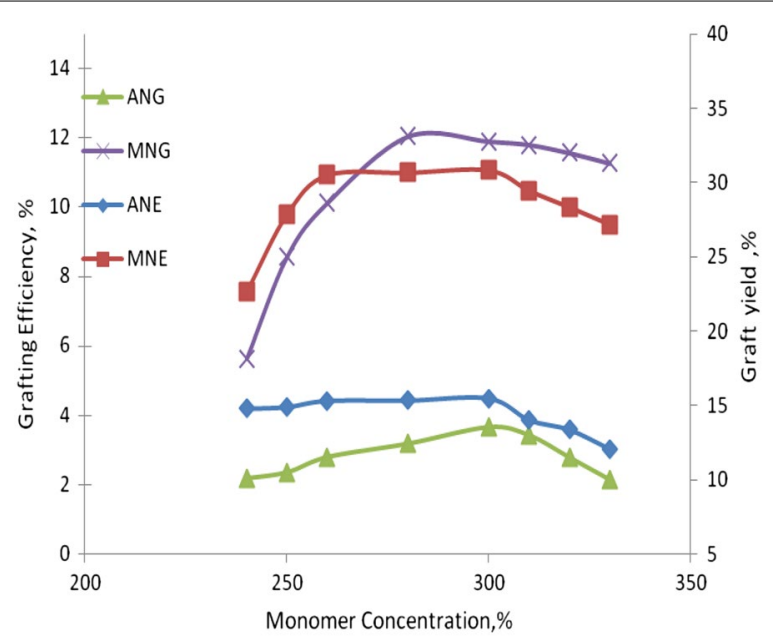

Fig. 1 Graft yield and grafting efficiency as a function of monomer concentration (ANG acrylonitrile grafting, MNG methacrylonitrile grafting, ANE efficiency of acrylonitrile, MNE efficiency of methacrylonitrile). 


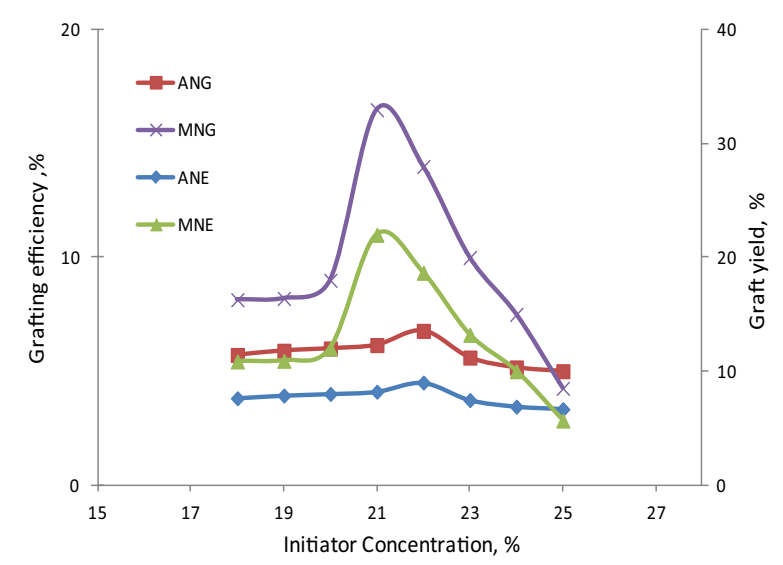

Fig. 2 Graft yield and grafting efficiency as a function of initiator concentration (ANG acrylonitrile grafting, MNG methacrylonitrile grafting, ANE efficiency of acrylonitrile, MNE efficiency of methacrylonitrile).

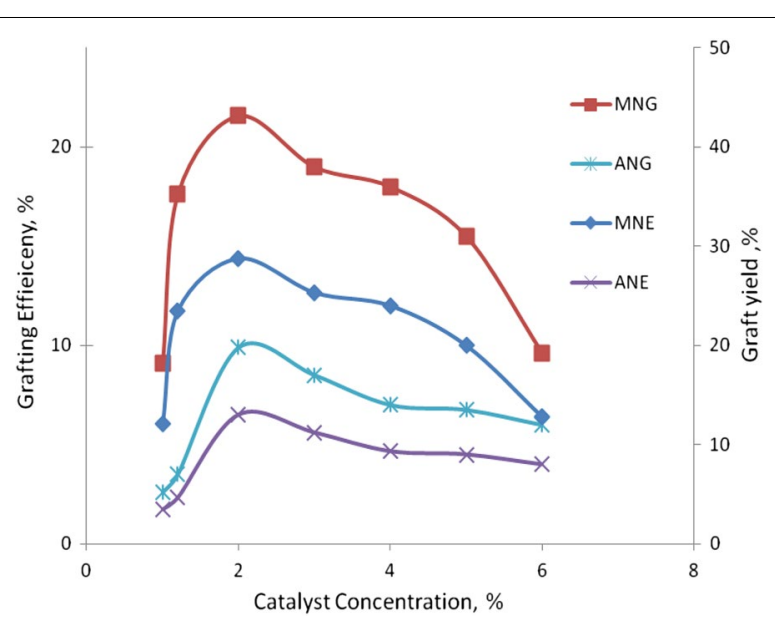

Fig. 3 Graft yield and grafting efficiency as a function of catalyst $\left(\mathrm{FeSO}_{4}\right)$ concentration ( $\mathrm{ANG}$ acrylonitrile grafting, MNG methacrylonitrile grafting, ANE efficiency of acrylonitrile, MNE efficiency of methacrylonitrile).

As the catalyst concentration increases, a greater number of Fe(II) ions is produced. Also, more reactive sites on the jute surface develop. Hence, grafting increases up to a certain concentration of catalyst. Beyond this concentration, graft yield and grafting efficiency decline. This is probably due to the formation of $\mathrm{Fe}(\mathrm{III})$ ions, which promote the premature termination of the growing grafted chain. Homopolymerization is also enhanced in presence of $\mathrm{FeSO}_{4}$ (Salam 2005). The effective concentrations of $\mathrm{FeSO}_{4}$ are $2 \%$ for both AN and MAN, and the corresponding graft yield and grafting efficiency rates are $17.78,43.15$ and $6.5,14.38 \%$ respectively.

Figure 4 shows that the graft yield increased with the increase of reaction time, up to 90 min for both AN and MAN. During this span of time, the activated monomer combined with the active sites of the fibre matrix. After $90 \mathrm{~min}$, the monomers found more reactive sites on the fibre backbone of cellulose and thus became homopolymerized (ELRafie 1994).

Again, at longer reaction times, the graft yield decreased. This could be due to the partial dissolution of the grafted fibre (Hebeish and Mehata 1968). The optimum 


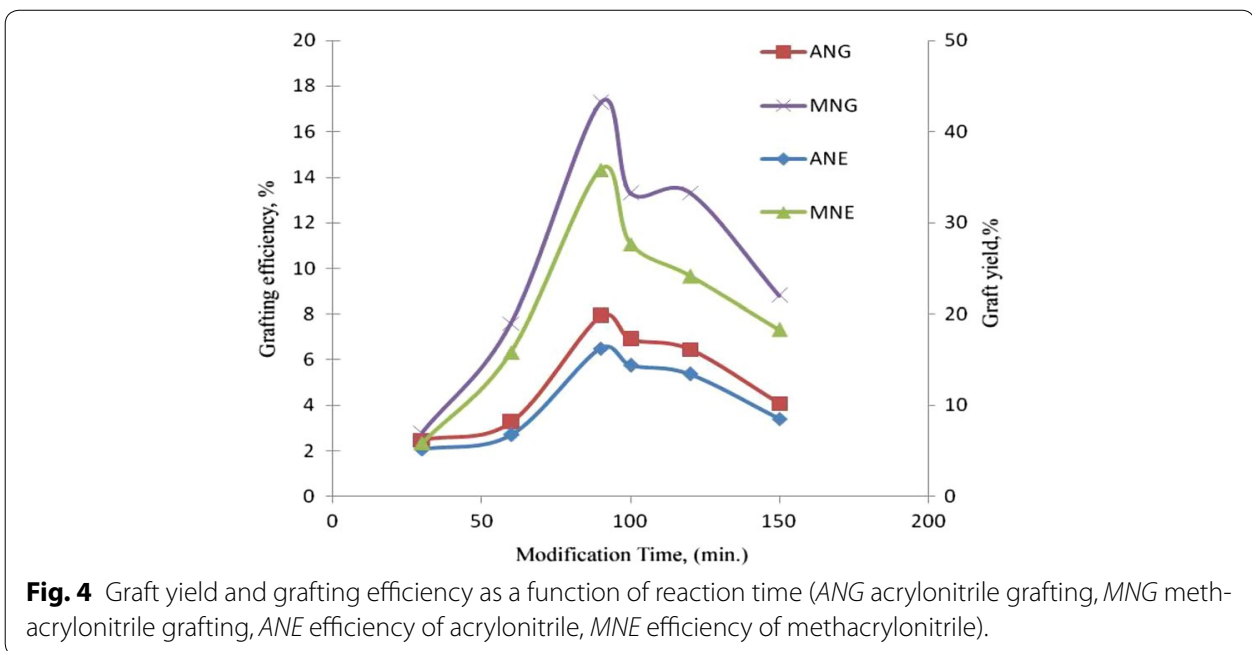

polymerization time was 90 min for both $\mathrm{AN}$ and MAN, while the corresponding graft yields were 19.78 and $43.15 \%$ respectively.

The effect of polymerization temperature on grafting of AN and MAN onto bleached jute fibre is shown in Fig. 5. It is seen that the grafting rate is low at low temperature, but at $80^{\circ} \mathrm{C}$, the graft yield and grafting efficiency peaked. The graft yield and grafting efficiency are 19.78, 6.59\% for AN and 43.15, 14.38\% for MAN, respectively, within an $80-90^{\circ} \mathrm{C}$ temperature range. The increase in graft yield and grafting efficiency up to optimum temperature may be ascribed as increase in the rate of production of active free radicals. These free radicals increase the number of grafting sites on the fibre backbone at a higher rate. Increase of temperature increases the rate of diffusion of monomer into the jute matrix, where grafting is also initiated by complex monomers (Rahman 1970).

The decrease in grafting efficiency and graft yield, beyond optimum temperature, may be attributed to the increase in activation energy for graft copolymerization. As

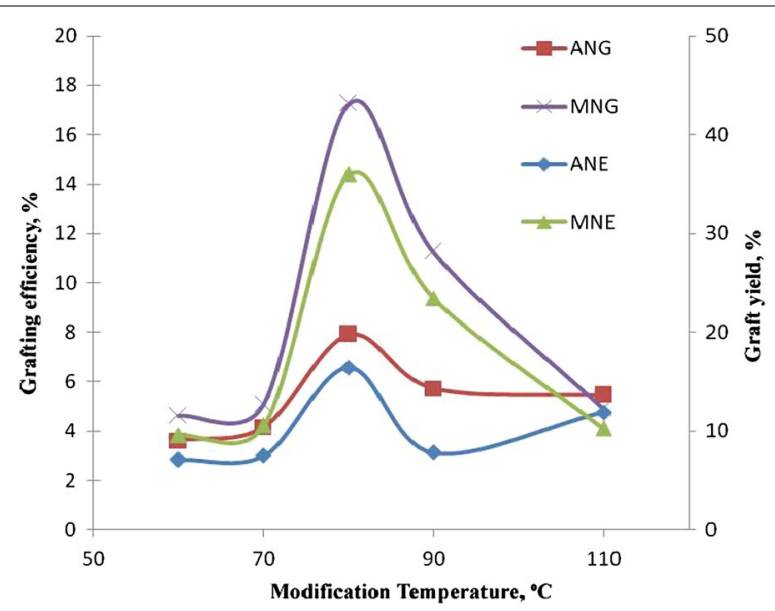

Fig. 5 Graft yield and grafting efficiency as a function of reaction temperature (ANG acrylonitrile grafting, MNG methacrylonitrile grafting, ANE efficiency of acrylonitrile, MNE efficiency of methacrylonitrile). 
discussed above, premature termination of growing grafted chains by excess Fe(III) ions, produced on the oxidation of $\mathrm{Fe}(\mathrm{II})$ ions, can also be a factor,

\section{Dyeing behavior of the grafted jute fibre}

The exhaustion of direct dyes by bleached and grafted jute fibres is listed in Table 1 . The dye exhaustion of the bleached jute fibre was higher than that of the modified fibre. The dye exhaustion decreased with an increase in the percent graft yield which occurred due to increase in hydrophobicity of grafted fibre. The dye absorption of fibre depends on the availability of the total external surface of the fibre pores or cavities in a fixed amount of the fibre and the attractive force between the fibres and dye ion. The bleached jute fibre had more available pores or cavities than the modified jute fibre as these, on grafting, were blocked. Hence, the dye exhaustion of the grafted jute fibre was less than that of the bleached jute fibre. The hydrophobic nature of the grafted jute fibre may also have increased with increases in the grafting amount. In such a case, the dye exhaustion of the bleached jute fibre would be higher than that of the grafted jute fibre.

\section{FTIR spectra of grafted jute fibre}

The infrared spectra of the bleached and grafted jute fibres are shown in the Fig. 6 . The IR spectra of bleached and grafted fibre were more or less similar. The FTIR spectra of the bleached and grafted jute fibre exert absorption peaks at $3,200-3,600 \mathrm{~cm}^{-1}$ due to

Table 1 Effect of dye absorption on dyeing of bleached and modified (AN and MAN) jute fibres

\begin{tabular}{lllll}
\hline Dyes & Name of dye & \multicolumn{2}{l}{ Dye exhaustion, \% } & \\
\cline { 3 - 5 } & & Bleached fibre & AN-grafted fibre & MN-grafted fibre \\
\hline Reactive dyes & Reactive Orange 14 & 47.18 & 46.00 & 44.4 \\
& Reactive Brown 10 & 46.40 & 40.28 & 38.23 \\
Direct dyes & Direct Orange 31 & 83.18 & 82.40 & 81.13 \\
& Direct Blue 1 & 94.15 & 90.38 & 89.23 \\
\hline
\end{tabular}

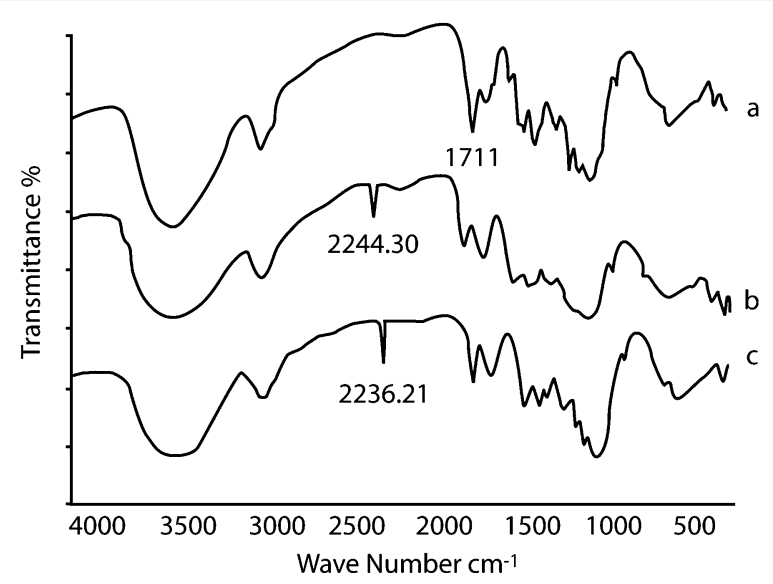

Fig. 6 FTIR spectra of (a) bleached jute, (b) acrylonitrile and (c) methacrylonitrile modified jute fibre. 
the $-\mathrm{OH}$ vibration, $2,820-3,050 \mathrm{~cm}^{-1}$ result from the $\mathrm{C}-\mathrm{H}$ stretching vibration, and the peak at $1,163 \mathrm{~cm}^{-1}$ due to the antisymmetric bridge $\mathrm{C}-\mathrm{O}-\mathrm{C}$ stretching's vibration of the cellulose pyranose ring. The presence of an absorption band near $1,711 \mathrm{~cm}^{-1}$ in the bleached jute fibre was probably due to the $\mathrm{C}=\mathrm{O}$ stretching of the ester group in celluloses (Tsuboi 1957). The new additional peaks in the grafted jute fibre were appeared at around 2,240 and 2,236 $\mathrm{cm}^{-1}$ for AN and MAN respectively indicated the presence of nitrile $(-\mathrm{C} \equiv N)$ group (Mondal et al. 2004; Khullar et al. 2008; Patra and Singh 1994).

\section{Determination of moisture content}

The moisture content of bleached fibre is $7.3 \%$ and that of modified fibre with AN and MAN fibres are 2.84 and $4.01 \%$, at $105^{\circ} \mathrm{C}$, respectively. These were measured by a moisture analyzer (Model: R.A 120-3, Kern, Germany).

\section{Thermal stability}

Figure $7 \mathrm{a}-\mathrm{c}$ represents the thermal stability properties of bleached, AN and MAN modified jute fibres. Each of the figure represents two thermogram curves, namely TGA and DTG. From Fig. $7 \mathrm{a}-\mathrm{c}$, it can be seen that the loss in weight is around $66.2 \%$ at $373.5^{\circ} \mathrm{C}$, $55.7 \%$ at $384^{\circ} \mathrm{C}$ and $62.1 \%$ at $389^{\circ} \mathrm{C}$ for bleached, AN-modified and MAN-modified jute fibres, respectively. The main peak at about $355^{\circ} \mathrm{C}$ was due to the decomposition of $\alpha$-cellulose (Fig. 7a). From the DTG curve in Fig. 7a-c, the rate of decomposition of bleached jute fibre was higher than that of AN- and MAN-modified jute fibres. Thus, the thermal stability of AN- and MAN-modified jute fibres are as high as 364 and $357^{\circ} \mathrm{C}$, respectively. These are higher than that of the unmodified fibres. This can be explained by the incorporation of nitrile monomer on to the jute fibre.

\section{Surface morphology}

Figure 8a-c shows the SEM micrograph of unmodified, AN-modified and MAN-modified jute fibres, respectively. The untreated cotton fibre shows the presence of a large number of micro-pores on its surface. After AN and MAN treatment, the jute fibre surfaces are coated with an outer layer of nitrile monomer (Rashidi et al. 2004) as observed in Fig. 8a, b. The ruptured surface of the modified fibre indicates the excess deposition of the nitrile monomer on the fibre hair, present in the jute fibre.

\section{Determination of breaking strength of the bleached and modified jute fibres}

It can be observed from Table 2 that the breaking load of modified jute fibre is higher that of the bleached fibre. It is also seen that the breaking load of MAN-modified fibre is higher (19.20 kg/Yarn) than that of AN-modified fibre (17.5 kg/Yarn). The difference may be due to the fact that poly-methacrylonitrile is a rigid polymer and poly-acrylonitrile is a soft polymer (Mondal et al. 2004).

\section{Conclusions}

In the present work, we have presented the graft copolymerization of nitrile monomers on to bleached jute fibre was carried out in the presence of a redox system, in an aqueous medium. The effect of the graft yield of the nitrile monomers on the jute fibre 

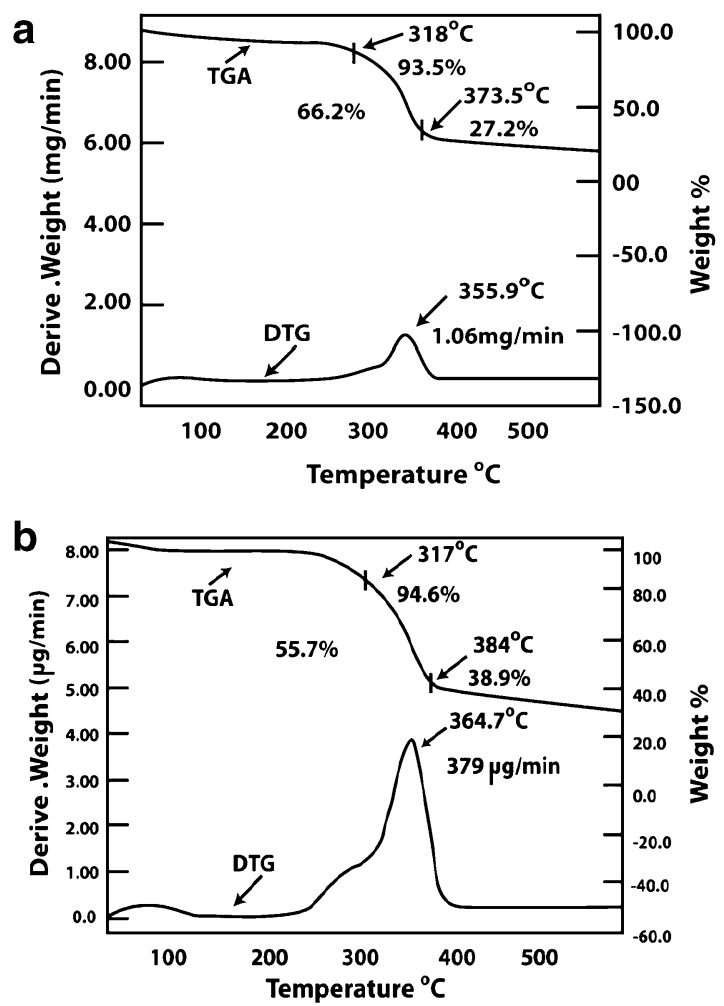

C

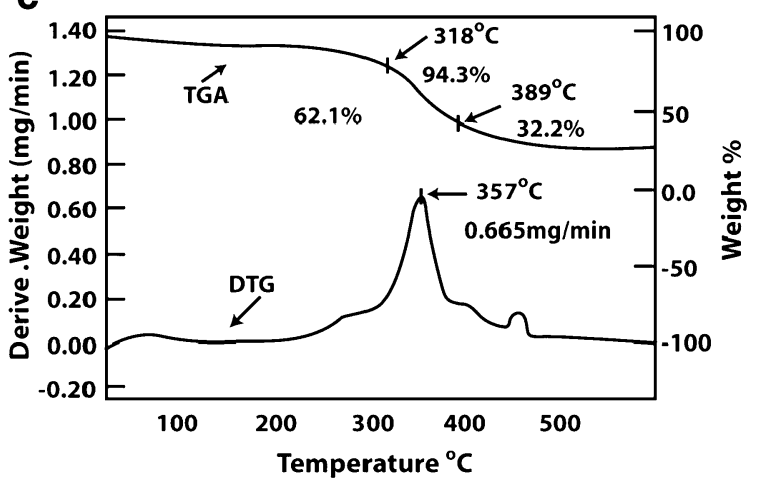

Fig. 7 TGA and DTG of $\mathbf{a}$ bleached jute fibre, $\mathbf{b}$ acrylonitrile grafted jute fibre and $\mathbf{c}$ methacrylonitrile grafted jute fibre.

depends on the parameter variables and on the jute fibre as well. The chemical attachment between the nitrile monomer and hydroxyl group of cotton fibres was evaluated by FTIR. The grafted fibre showed improved physicochemical properties like tensile 

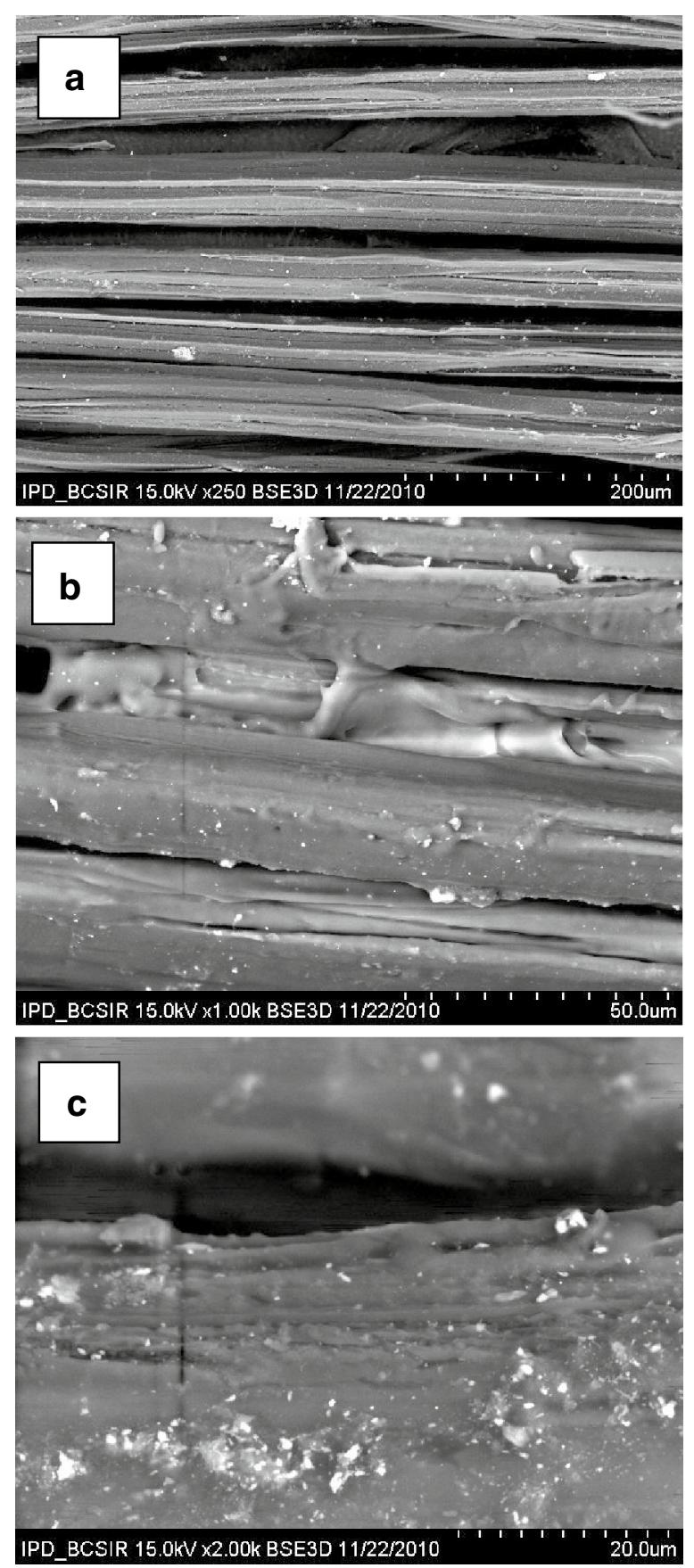

Fig. 8 SEM of $\mathbf{a}$ bleached fibre, $\mathbf{b}$ acrylonitrile grafted jute fibre and $\mathbf{c}$ methacrylonitrile grafted jute fibre.

Table 2 Breaking strength of bleached and modified fibres

\begin{tabular}{lll}
\hline Bleached fibre & \begin{tabular}{ll} 
Modified fibre \\
\cline { 2 - 3 }
\end{tabular} & $\begin{array}{l}\text { AN-grafted fibre } \\
\text { fibre }\end{array}$ \\
\hline $\begin{array}{l}\text { Breaking load (kg/Yarn) } \\
16.02 \pm 0.42\end{array}$ & $17.5 \pm 0.39$ & $19.20 \pm 0.56$ \\
\hline
\end{tabular}

Results are expressed as mean \pm standard deviation; $n=4$. 
strength, moisture absorption and thermal stability. Thus a new type of jute fibre was obtained through graft polymerization. Such a process can make jute more suitable, as an input, in the manufacture of garments, home textiles etc.

Authors' contributions

IHM designed the paper, performed the literature survey and completed the paper. KI performed the experiments and analyzed the data in consultation with IHM. All authors read and approved the final manuscript.

\section{Acknowledgements}

The authors would like to acknowledge the Ministry of Education in Bangladesh for funding the project as Higher Education Research Grant in 2014 (Memo no.: 37.01.0000.078.02.018.13-206(38)/6-35, 2014).

\section{Compliance with ethical guidelines}

Competing interests

The authors declare that they have no competing interests.

Received: 26 May 2015 Accepted: 28 July 2015

Published online: 25 August 2015

\section{References}

Alam, M. S., \& Khan, G. M. A. (2007). Chemical analysis of okra bast fiber (Abelmoschus esculentus) and its physicochemical properties. Journal of Textile and Apparel Technology and Management, 5(4), 1-9.

Bakr, N. A., Chee, C. Y., Abdullah, L. C., Ratnam, C. T., \& Ibrahim, A. (2015). Thermal and dynamic mechanical properties of grafted kenaf filled poly(vinyl chloride)/ethylene vinyl acetate composites. Materials and Design, 65, 204-211.

Bianchi, E., Bonazza, A., Marsano, E., \& Russo, S. (2000). Free radical grafting onto cellulose in homogeneous conditions. 2. Modified cellulose-methyl methacrylate system. Carbohydrate Polymer, 41, 47-53.

Bicak, N., Sherrington, D. C., \& Senkal, B. F. (1999). Graft copolymer of acrylamide onto cellulose as mercury selective sorbent. Reactive Functional Polymer, 41, 69-76.

Dong, A., Fan, X., Wang, Q., Yu, Y., \& Cavaco-Paulo, A. (2015). Hydrophobic surface functionalization of lignocellulosic jute fabrics by enzymatic grafting of octadecylamine. International Journal of Biological Macromolecules, 79, 353-362.

El-Rafie, M. H., Abdul Hafiz, S. A., Hassan, S. M., \& Hebeish, A. (1994). Grafting of methacrylic acid to loomstate viscose fabric using $\mathrm{KMnO}_{4} / \mathrm{NaHSO}_{3}$ system. Polymers and Polymer Composites, 2, 99-104.

El-Shekeil, Y. A., Sapuan, S. M., Jawaid, M., \& Al-Shuja'a, O. M. (2014). Influence of fiber content on mechanical, morphological and thermal properties of kenaf fibers reinforced poly(vinyl chloride)/thermoplastic polyurethane poly-blend composites. Materials and Design, 58, 130-135.

Farouqui, F. I., \& Mondal, Md I H. (1989). Scouring and bleaching of jute fiber in relation to its strength (pp. 1-8). XVII: The Rajshahi University Studies Part-B.

Fatimah, A. B. N., Ching, Y. C., Chuah, A. L., Thevy, R. C., \& Azowa, I. N. (2014). Effect of methyl methacrylate grafted kenaf on mechanical properties of polyvinyl chloride/ethylene vinyl acetate composites. Composites: Part A, 6, 45-50.

Gonaslves, K. E., \& Mungara, P. M. (1996). Synthesis and properties of degradable polyamides and related polymers. Trends in Polymer Science, 4(1), 25-31.

Hebeish, A., \& Mehata, P. C. (1968). Cerium-initiated grafting of acrylonitrile on to cellulosic material. Journal of Applied Polymer Science, 12, 625-1647.

Hebiesh, A., Katouch, A., \& EL-Rafie, M. H. (1971). Graft co-polymerization of vinyl monomer with modified cotton. II Grafting of acrylonitrile and methyl methacrylate on acetylated cotton. Journal of Applied Polymer Science, 15, 1-24.

Huque, M. M., Habibuddowla, M. D., Mahmood, A. J., \& Mian, A. J. (1980). Graft-copolymerization onto jute fiber--ceric ion-initiated graft-copolymerization of methyl-methacrylate. Journal of Polymer Science Part A Polymer Chemistry Edition, 18, 1447-1458.

International Standard ISO 5081-1977(E). (1997). Determination of breaking strength and elongation (Strip method). Switzerland: International Organisation for Standardization.

Khullar, R., Varshney, V. K., Naithani, S., \& Soni, P. L. (2008). Grafting of acrylonitrile on to cellulosic material derived from bamboo (Dendrocalamus strictus). Express Polymer Letters, 2, 12-18.

Mcdowall, D. J., Gupta, B. S., \& Stannett, V.T. (1984). Grafting of vinyl monomers to cellulose by ceric ion inhibition. Progress of Polymer Sciences, 10, 1-50.

Mishra, S., Misra, S. M., Tripathy, S. S., Nayak, S. K., \& Mohanty, A. K. (2001). Graft copolymerization of acrylonitrile on chemically modified sisal fibres. Macromolecular Materials and Engineering, 286(2), 107-113.

Misra, M., Mohanty, A. K., \& Singh, B. C. (1987). A study on grafting of methyl methacrylate on to jute fibre $\left(\mathrm{S}_{2} \mathrm{O}_{8}{ }^{2-}\right.$ thio system). Journal of Applied Polymer Science, 33, 2809-2819.

Mohanty, A. K., Khan, M. A., \& Hinrichsen, G. (2000). Influence of chemical surface modification on the properties of biodegradable jute fabrics-polyester amide composites. Composites: Part A, 31, 143-150.

Mohanty, A. K., Singh, B. C., \& Mirsha, B. C. (1986). Vanadium-cyclohexane-initiated graft copolymerization of methyl methacrylate on to jute fibre. Journal of Applied Polymer Science, 31, 1763-1769.

Mondal, Md I H. (2013). Grafting of methyl acrylate and methyl methacrylate on to jute fiber: physico-chemical characteristics of the grafted jute. Journal of Engineered Fibers and Fabrics, 8(3), 42-50.

Mondal, Md I H, Alam, R., \& Sayeed, M. A. (2004). Graft copolymerization of nitrile monomers on to bleached jute fibre using potassium persulfate system and their textile characteristics. Journal of Applied Polymer Science, 92, 3622-3629. 
Mukhopadhyay, S., Prasad, J., \& Chatterjee, S. R. (1975). Grafting of acrylic acid on to methylcellulose. Die Macromoleculare Chemie, 176, 1-7.

Okieimen, E. F. (1987). Studies on the graft copolymerization of cellulosic materials. European Polymer Journal, 23, 319-322.

Ouajai, S., Hodzic, A., \& Shanks, R. A. (2004). Morphological and grafting modification of natural cellulose fibers. Journal of Applied Polymer Science, 94, 2456-2465.

Ouajai, S., Hodzic, A., \& Shanks, R. A. (2007). Morphological and grafting modification of natural cellulose fibras. Materials Letters, 61, 2456-2465.

Patra, C. M., \& Singh, B. C. (1994). Influence of N-acetylglycine on the kinetics of ceric ion-initiated graft-copolymerization of acrylonitrile and methyl-methacrylate on to jute fibres. Journal of Applied Polymer Science, 52, 1557-1568.

Rahman, M. V. (1970). Thermogravimetric and differential thermal analysis of cellulose, hemicelluloses and lignin. Journal of Applied Polymer Science, 14, 1323-1337.

Rashidi, A., Moussavipourgharbi, H., \& Mirjalili, M. (2004). Effect of low-temperature plasma treatment modification of cotton and polyester fabrics. Indian Journal of Fibre \& Textile Research, 29, 74-78.

Salam, M. A. (2005). Graft copolymerization of methacrylonitrile monomer on to sulfonated jute cotton-blended fibre. Journal of Textile and Apparel, Technology and Management, 4, 45-56.

Samal, R. K., Dash, S., \& Swain, A. K. (1989). Graft copolymerization of methyl acrylamide on to jute fibers initiated by peroxydisulfate catalysed by Fe(III). Polymer Journal, 21, 821-828.

Samal, B. B., Sahu, S., Chinara, B. B., Nanda, S., Otta, P. K., Mohapatro, L. M., et al. (1988). Grafting of vinyl monomers onto sisal fiber in aqueous solution. Journal of Polymer Science Part A Polymer Chemistry Edition, 26, 3159-3166.

Samal, R. K., Samantaray, H. S., \& Samal, R. N. (1986). Graft copolymerization with a new class of acidic peroxo salt IV. Grafting of acrylamide on to jute fibre using potassium mono persulphate: catalyzed by Fe(II). Polymer Journal, 18 , $471-478$.

Tsuboi, M. (1957). Infrared spectrum and crystal structure of cellulose. Journal of Polymer Science, 2, 157-171.

\section{Submit your manuscript to a SpringerOpen ${ }^{\circ}$ journal and benefit from:}

- Convenient online submission

- Rigorous peer review

- Immediate publication on acceptance

- Open access: articles freely available online

- High visibility within the field

Retaining the copyright to your article

Submit your next manuscript at $>$ springeropen.com 